\title{
GINSENOSIDE RB1, A COMPONENT OF PANAX GINSENG, AMELIORATES SELENIUM INDUCED RENAL TOXICITY IN BROILERS
}

\author{
Shimaa A Elgaml \\ Clinical Pathology Department, Faculty of Veterinary Medicine, Zagazig University, Zagazig, Sharkyia, Egypt
}

\begin{abstract}
Panax Ginseng (PG) has been widely used as natural product for many years with limited knowledge on its effect on renal dysfunction. Ginsenoside (Rb1) is the most clinically effective derivative of ginseng. The aim of this study was to investigate the protective role of ginsenoside $\mathrm{Rb} 1$ on selenium induced renal toxicity in broilers. Forty, one day old chicks acclimatized for 14 days and divided into four groups; negative control, Selenium (Se) treated ( $0.48 \mathrm{mg} \mathrm{Na} 2 \mathrm{SeO}_{3} / \mathrm{kg}$ b.wt.), Rb1 plus Se

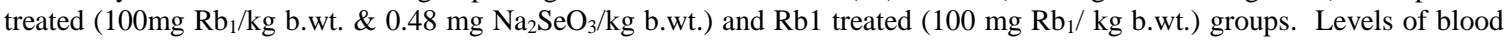
urea nitrogen, uric acid, creatinine, calcium $(\mathrm{Ca})$, phosphorus $(\mathrm{P})$, magnesium $(\mathrm{Mg})$, sodium $(\mathrm{Na})$, potassium $(\mathrm{K})$, catalase (CAT), superoxide dismutase (SOD), glutathione peroxidase (GPx) and malondialdehyde (MDA) were estimated. The pretreatment of chickens with Rb1 significantly ameliorate the degenerative effect of selenium over the biochemical parameters, electrolytes and improves the antioxidant activity. Taken together, it could be concluded that the pretreatment of ginsenoside $\mathrm{Rb} 1$ has a protective effects against renal injury induced by sodium selenite toxicosis. The ginsenoside Rb1 is thus can be utilized as a useful natural product tool to protect against selenium toxicosis.
\end{abstract}

Key words: Panax ginseng, Ginsenoside Rb1, Selenium toxicity, Kidney function, antioxidant, Chicken

\section{INTRODUCTION}

Selenium is a natural food supplement in animal's diets, but it can also be a toxin. The difference between an effective or safe dose and a toxic dose of selenium is relatively small (MacFarquhar et al., 2010). Selenium is found in steel and copper alloys, glass, paint manufacturing and nutritional supplements (Barceloux, 1999). A serious problem came from the environmental exposure to selenium due to industrial accidents, poisonings and the dietary abuse of selenium rich plants (Aldosary et al., 2012). The kidneys retain a large amount of absorbed Se along with the liver, cardiac and skeletal muscle. Still, little information is available on the effect of selenium toxicity on the kidney and oxidative stability of reactive oxygen species in broiler birds (Ryu et al., 2005).

Panax ginseng (Korean ginseng) is a medicinal plant thought to be protective against several diseases as cardiovascular disease and diabetes (Han et al., 2006). Most of the pharmacological actions of ginseng are attributed to a variety of ginsenosides (Huang et al., 2005). Ginseng has many medicinal effects on immune response, sexual function, physiological homeostasis, enhance vital energy besides, it possesses anti-stress, antitumor properties, anti-apoptotic effects on the kidney (Attele et al., 1999; Kalkan et al., 2012).

Ginsenoside ( $\mathrm{Rb} 1)$ is considered one of the best clinically effective constituent of ginseng as it possesses antioxidant, anti-inflammatory and anti-apoptosis effects (Cheng et al., 2005). It has been reported that Rb1 attenuate renal apoptosis and oxidative damage (Xie et al., 2009). Science the Rb1 play a role in oxidative stress, it is expected to have an important roles in the renal protective effects with oxidative damage.

In the present study, we investigated the protective effects of Rb1 against selenium-induced renal dysfunction and explored the antioxidant status. Renal damage was assessed by serum biochemical analysis, renal function tests and examining the potential antioxidant activity. Significant protection from selenium-induced renal injury has been showed by Rb1 with the ability to protect against the induced oxidative damage in broiler chicken.

\section{MATERIALS AND METHODS \\ Materials}

Chickens Forty, one-day-old, commercial boiler chickens (Hubbard strain) were purchased from Al-Kahira Poultry Company. Chickens were maintained at the Laboratory Animal Center, College of Veterinary Medicine, Zagazig University and were kept in clean well ventilated cages under standard managerial, environmental and hygienic conditions. Chickens were divided into 4 main groups, acclimatized for 14 days prior the experiment

*Corresponding e-mail address: drshimaa_68@yahoo.com 


\section{Shimaa A Elgaml}

and maintained on a commercial well balanced ration, formulated to meet the nutrient requirement of chickens during the experimental period according to recommendations of the national research council (NRC, 1994), and drinking water was given ad.libitium throughout the experimental period.

Sodium selenite $\left(\mathrm{Na}_{2} \mathrm{SeO}_{3}\right)$ was purchased from Sigma Chemicals. It was used as $1 / 20^{\text {th }}$ of $\mathrm{LD}_{50}$ of $\mathrm{Na}_{2} \mathrm{SeO}_{3}$ of broiler chickens, at a dose of $0.48 \mathrm{mg} / \mathrm{kg}$ b.wt., in the diet. (Kumar, 2013).

Panax ginseng root extract (Ginsenoside $\mathrm{Rb}_{1}=$ saponin of Panax ginseng) was obtained from Sigma Chemicals. A dose of $100 \mathrm{mg} / \mathrm{kg}$ b.wt., in the diet was used for the experiment (Karakus et al., 2011).

\section{Methods \\ Experimental design}

The experiment procedures used in this experiment were carried out and approved by the local institutional of animal care and veterinary committee of Faculty of Veterinary Medicine, Zagazig University, Egypt. Chickens were divided into four groups as following. Group I: $(n=10)$, negative control group, chickens were fed on a commercial basal balanced clean ration, supplemented with clean water, under hygienic measurements without any treatment for 30 days. Group II: ( $n=10)$, Se-intoxicated group, chickens were fed on a commercial basal diet, which mixed with $\mathrm{Na}_{2} \mathrm{SeO}_{3}$ at a concentration of $(0.48 \mathrm{mg} / \mathrm{kg}$ b.wt.) for 30 days. Group III: $(\mathrm{n}=10), \mathrm{Rb} 1$ plus Se treated group, chickens were fed with a commercial basal diet, which mixed with Rb1 at a concentration of (100 $\mathrm{mg} / \mathrm{kg}$ b.wt.) for 10 days, then feeding with diet mixed with $\mathrm{Na}_{2} \mathrm{SeO}_{3}$ at a concentration of $(0.48 \mathrm{mg} / \mathrm{kg}$ b.wt. $)$ for 20 days. Group IV: $(n=10)$, Rb1 treated group; chickens were fed on a commercial basal diet, which mixed with $\mathrm{Rb} 1$ at a concentration of (100 $\mathrm{mg} / \mathrm{kg}$ b.wt.) for 30 days.

\section{Blood sampling}

The blood samples were collected on the $31^{\text {th }}$ day from the wing vein. $5 \mathrm{ml}$ of blood was collected without anticoagulant into a clean dry centrifuge tube and allowed to clot for $30 \mathrm{~min}$ at room temperature. Blood samples were centrifuged at $3000 \mathrm{rpm}$ for $5 \mathrm{~min}$. Clear sera were separated and used for different biochemical analysis.

\section{Estimation of biochemical parameters}

All parameters were colorimetrically measured using commercial kits provided by (BioMérieux, Marcy, L'Etoile, France). All analysis was done using Spectrophotometer 5010 v5 $5^{+}$, (RIELE GmbH \& Co, Berlin, Germany) for biochemical serum analysis. Blood urea nitrogen (Christian et al., 1965), uric acid (Kageyama, 1971) serum creatinine (Heinegard and Tiderstrom, 1973), electrolytes, such as serum calcium (Ca), inorganic phosphorus (P) and magnesium (Mg) (Berti et al., 1988; Ripoll, 1976; Smith, 1955) were measured. Serum sodium and potassium concentrations were assayed using flame photometer (Verzhikovskaia and Popov, 1963).

\section{Antioxidants and (MDA) lipid peroxidation Assay}

Kidney was collected from all groups on days 31. One gram of each kidney sample added to $9 \mathrm{ml}$ of normal saline $(0.9 \%)$ and homogenized using tissue homogenizer, and centrifuged at $3000 \mathrm{rpm}$ for 15 minutes. The supernatant was collected and used for antioxidants estimation (CAT), (SOD), (GPx) and the marker of lipid peroxidation (MDA) according to, (Sidhu et al., 2005). The catalase activity (CAT) (Aebi 1984), superoxide dismutase (SOD) (Weydert and Cullen, 2010), Glutathione peroxidase (GPx) (Weydert and Cullen, 2010) and malondialdehyde (MDA) (Valenzuela, 1991) were determined.

\section{Statistical analysis}

Statistical Analysis System software package was used to analyze the data by one-way analysis of variance ANOVA (Bewick et al., 2004). The significant differences between means were determined at a level of $(\mathrm{P}<0.05)$. All data showed a normal distribution and passed equal variance testing. Differences between means were assessed using Tukey's honestly significant difference test for post hoc multiple comparisons. Data are expressed as the mean \pm SEM. 
RESULTS

\section{Evaluation of kidney markers}

The effects of sodium selenite intoxication as well as the preventive effects of ginsenoside Rb1 on kidney markers are shown in Fig. 1. Significant $(p<0.05)$ increases in the level of blood urea nitrogen, uric acid and creatinine levels of chickens were recorded in sodium selenite intoxicated group as compared to negative control group. On the other hand, marked improvement has been detected when treatment with ginsenoside Rb1, significant decrease $(\mathrm{p}<0.05)$ of blood urea nitrogen, uric acid and creatinine of chickens given $\mathrm{Rb} 1$ and Se was detected when compared with the Se intoxicated group. Significant increase $(\mathrm{p}<0.05)$ in the levels of uric acid and creatinine in the ginsenoside $\mathrm{Rb} 1$ treated group when compared with Rb1+Se treated group, but the levels are still not significant when compared with the negative control group.

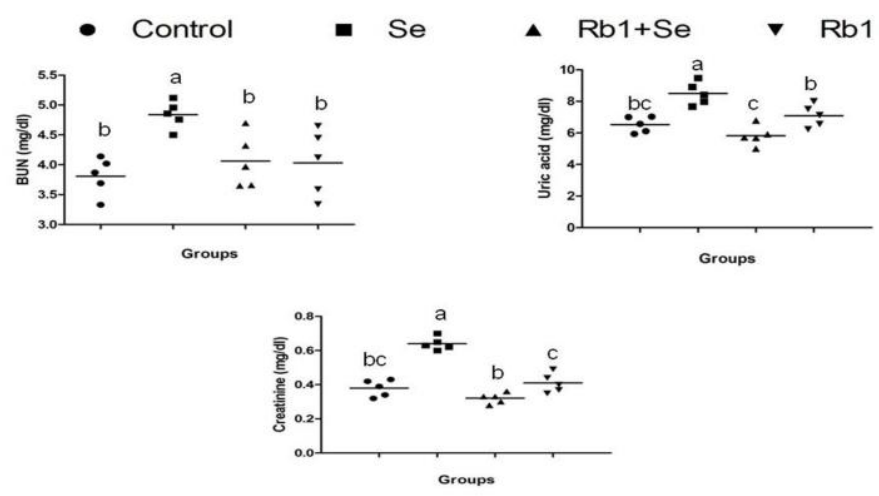

Fig. 1. Effect of selenium and ginsenoside Rb1 on the levels of kidney markers. Changes in the levels of blood urea nitrogen, uric acid and creatinine $(\mathrm{mg} / \mathrm{dl})$ were observed. Values were significantly different at $(\mathrm{P}<0.05)$ when compared with the negative group. Data are expressed as means \pm SEM. Bars showing the same letter $(a, b$, c) are not significantly different.

\section{Evaluation of serum electrolytes}

The effects of sodium selenite intoxication as well as the preventive effects of ginsenoside Rb1 on the serum electrolyte are shown in Fig. 2. Significant $(\mathrm{p}<0.05)$ decrease in calcium and phosphorus, magnesium, sodium was recorded in sodium selenite intoxicated group. Significant increase $(\mathrm{p}<0.05)$ in serum potassium level was also reported in the sodium selenite intoxicated group. Treatment with ginsenoside $\mathrm{Rb} 1$ showed significant improvement. Significant increase $(\mathrm{p}<0.05)$ was observed in calcium, phosphorus, magnesium, sodium towards the normal level. Similarly, significant decrease $(p<0.05)$ in serum potassium level was observed. Meanwhile, significant decrease $(\mathrm{p}<0.05)$ in the level of potassium in the ginsenoside $\mathrm{Rb} 1$ treated group when compared with $\mathrm{Rb} 1+\mathrm{Se}$ treated group, but the levels are still non-significant when compared with the negative control group.

\section{Evaluation of renal antioxidant and lipid peroxidation profile}

Effects of sodium selenite intoxication and the preventive effects of ginsenoside $\mathrm{Rb} 1$ on the renal antioxidant and lipid peroxidation profile are shown in figure 3. Significant decrease $(\mathrm{p}<0.05)$ in the levels of renal CAT, SOD and GPx sodium was reported in the sodium selenite intoxicated group. On the other hand, significant increase $(\mathrm{p}<0.05)$ in the activity of CAT, SOD and GPx was detected towards the normal control level. Meanwhile, the level of renal CAT in the ginsenoside Rb1 treated group was significantly decrease $(\mathrm{p}<0.05)$ when compared with $\mathrm{Rb} 1+\mathrm{Se}$ treated group, but the levels are still non-significant when compared with the negative control group. Significant increase $(\mathrm{p}<0.05)$ in MDA level was observed in sodium selenite intoxicated group. Significant decrease in MDA level was detected in other treated groups. 
Shimaa A Elgaml

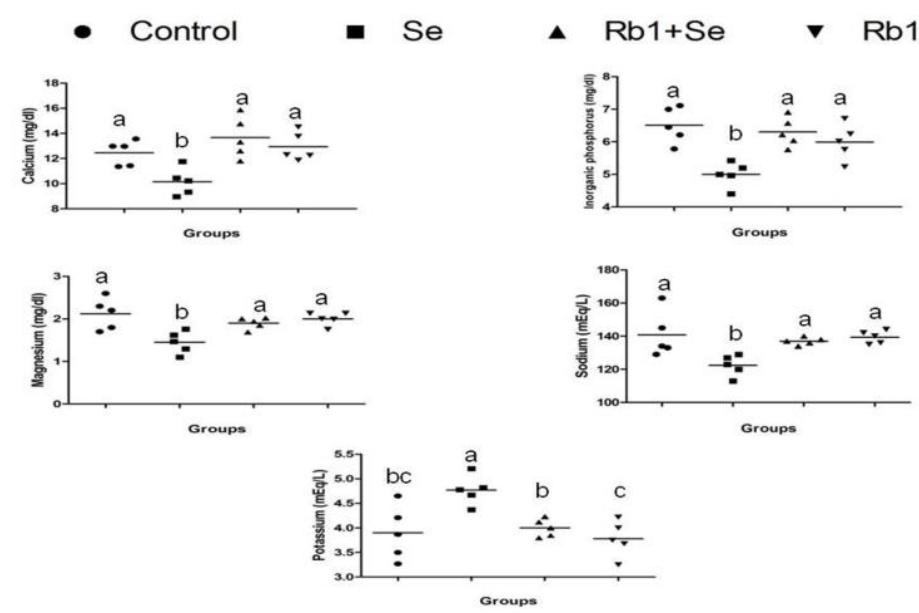

Fig. 2. Effect of selenium and ginsenoside Rb1 on the levels of serum electrolytes. Changes in $\mathrm{Ca}(\mathrm{mg} / \mathrm{dl}), \mathrm{P}$ $(\mathrm{mg} / \mathrm{dl}), \mathrm{Mg}(\mathrm{mg} / \mathrm{dl}), \mathrm{Na}(\mathrm{mEq} / \mathrm{l})$ and $\mathrm{K}(\mathrm{mEq} / \mathrm{l})$ were reported. Values were significantly different at $(\mathrm{P}<0.05)$ when compared with the control group. Data are expressed as means \pm SEM. Bars showing the same letter (a, b, c) are not significantly different.

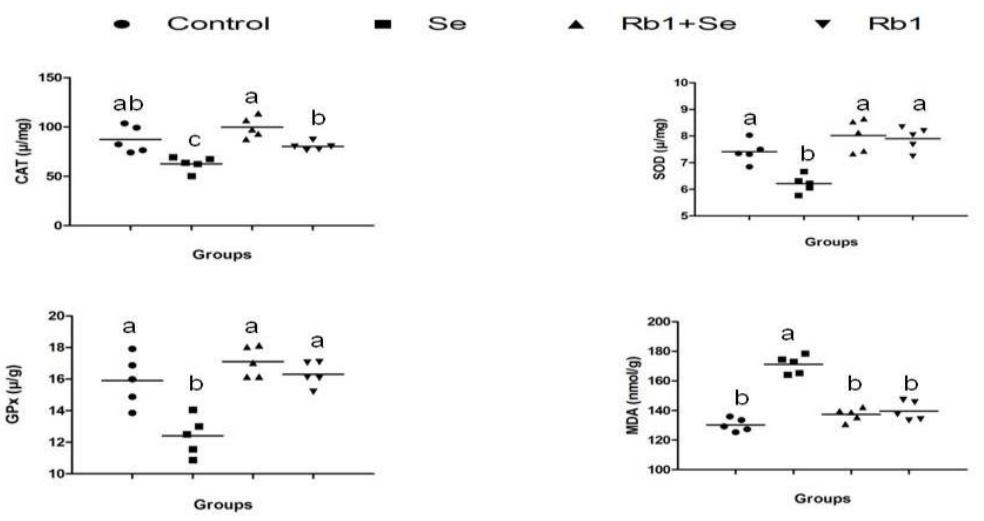

Fig. 3. Effect of selenium and ginsenoside Rb1 on the levels of serum antioxidant activity and lipid peroxidation profile. Changes in the levels of CAT $(\mu \mathrm{l} / \mathrm{mg})$, SOD $(\mu \mathrm{l} / \mathrm{mg})$, GPx $(\mu \mathrm{l} / \mathrm{g})$ and MDA (nmol/g) were observed. Values were significantly different at $(\mathrm{P}<0.05)$ when compared with the control group. Data are expressed as means \pm SEM. Bars showing the same letter $(\mathrm{a}, \mathrm{b}, \mathrm{c})$ are not significantly different.

\section{Discussion}

Selenium toxicity is found in poultry flocks causing tissue lesions, oxidative damage, apoptosis of splenocytes, and deaths (Peng et al., 2012). Excess selenium can cause growth depression, anemia, impaired immune function and reduced egg production (Zwolak and Zaporowska, 2012). Recently, high concentrations of selenium is used as hepatic toxins in the research studies (Xu et al., 2014). Several studies previously reported the markers to be included in kidney function tests. One group stated that uremia, hyperuricemia, increase in the serum creatinine level with calcium and phosphorus imbalance were detected in renal dysfunction (Chandra et al., 1985). Others stated that blood urea nitrogen, uric acid and serum creatinine levels are considered significant markers of renal 


\section{Ginsenoside, panax ginseng, ameliorates selenium induced renal toxicity in broilers}

dysfunction (Gowda et al., 2010). The production of reactive oxygen species by renal cortical mitochondria and the involvement of oxidative stress to renal toxicity could be the reason for the kidney dysfunction (Hoffman, 2002).

Blood urea nitrogen (BUN) has little value in the configuration of avian renal disease but it is a sensitive detector for hydration state. The decrease in BUN associated with Se toxicity may be attributed to dehydration. About $99 \%$ of BUN is reabsorbed in the dehydrated bird (Lumeij, 1987). Excretion of uric acid depends on the urine flow and therefore is unaffected by moderate changes in glomerular filtration (Chandra et al., 1985). Hyperuricemia may be seen with severe dehydration, due to hyperglycemia causing increased urination and fluid loss, associated with selenium toxicity (Jones, 1999; Lumeij, 1987). The uric acid significantly increases with renal disease if there is extensive tubular damage (Chandra et al., 1985). Ginsenoside $\mathrm{Rb}_{1}$ significantly improves the elevated levels of blood urea nitrogen, serum uric acid and creatinine levels. The mechanism by which it prevents Se-induced nephrotoxicity is not well studied. However the saponins in the ginsenoside $\mathrm{Rb}_{1}$ may have improved the kidney function through several antioxidant properties such as free radical scavenging activity or the inhibition of the formation of oxidized product. Panax Ginseng in general has been shown to have antioxidant and anti-inflammatory effects (Lee and Son, 2011). Also recent studies have provided a great support for evidencing the protective effects of ginseng on kidney damage (Kang et al., 2013). In our investigation, ginsenoside $\mathrm{Rb} 1+\mathrm{Se}$ and ginsenoside $\mathrm{Rb} 1$ treated groups showed an improvement in kidney function tests when compared with control. Changes in uric acid and creatinine between those treated groups have been detected, but these changes were not significant when compared with control. There is no clear reason to describe those changes other than the ginsenoside Rb1-Se interaction, which might play a role in this case.

Avian kidney cannot concentrate the electrolytes much above normal levels (Chandra et al., 1985). The renal dysfunction in birds is associated with hypocalcemia, hypomagnesemia, hyponatremia and hyperkalemia (Lierz, 2003). Electrolyte imbalance such as hypocalcemia, Hypophosphatemia, hypomagnesemia, hyponatremia with hyperkalemia was reported in our study. Selenium intoxication is associated with osmotic diuresis due to hyperglycemia which cause marked urinary loses of water, electrolytes and aggravated urinary excretion of ketones with additional electrolyte loss (Steinbrenner et al., 2011). Hypocalcemia was a result of metabolic changes such as metabolic acidosis, and impaired parathormone hormone (Desta et al., 2011). Hypomagnesemia may be due to the hyperglycemia and glycosuria-related hypermagnesuria (Steinbrenner et al., 2011). Hyponatremia may be due to the alteration in the sodium channel proteins in the collecting ducts and distal convoluted tubules leading to increased fractional excretion of sodium in urine. Translocation of $\mathrm{Na}+, \mathrm{K}+-$ ATPase pumps from the baso-lateral membrane of proximal convoluted tubules to the cytosol leads to a decrease in sodium pumping from renal tubules to the blood (Kamble et al., 2009). On the other hand, hyperkalemia may be attributed to the condition of acidosis with extracellular migration of potassium (Nuttall, 2006). Ginsenoside $\mathrm{Rb}_{1}$ resulted in amerilation of electrolyte imbalance. This may have resulted from a decrease in urine volume, which resulted in the improvement of the metabolic abnormalities (Kang et al., 2008).

Electrolytes levels in ginsenoside $\mathrm{Rb} 1+\mathrm{Se}$ and ginsenoside Rb1 treated groups where significantly improved when compared with control. A change in potassium level between those treated groups has been detected, but the change was not significant when compared with control. It is expected that Se toxicity might play a role in releasing potassium from the body cells to the blood stream, the maldistribution of potassium between intra- and extracellular space predisposed to hyperkalemia (Lehnhardt and Kemper, 2011). This could describe the change in potassium level between the two groups.

Selenium has a role in triggering oxidative stress in hepatic and renal tissues (Elgaml, 2014; Kamble et al., 2009; Padmaja and Raju, 2005). Selenium triggering kidney diseases, primarily by free radical generation and the depletion of antioxidant status, causes damage in the cell membrane and the organelles of the hepatocyte and kidney (Manikandan et al., 2010). It induces oxidative damage by increasing the production of ROS (Maraldi et al., 2011) and decreasing the biological activities of some antioxidants, such as CAT, SOD and GPx (Zikic et al., 1998). Se intoxication increases lipid peroxidation and suppresses the antioxidant defense mechanisms in kidney tissue (Agarwal and Behari, 2007; Atencio et al., 2009). The increased activity of CAT, SOD and GPx were detected in kidney tissues of Rb1 treated groups when compared with $\mathrm{Se}$ intoxicated group. These antioxidants can prevent or decrease the harmful effects and ROS in kidney tissue. Ginsenoside Rb1 decreased the MDA concentration in the $\mathrm{Se}+\mathrm{Rb} 1$ and $\mathrm{Rb} 1$ groups. The role of $\mathrm{Rb} 1$ in preventing LPO, protecting the integrity and functioning of kidney tissues is of important reflection in protection against selenium toxicity. Ginsenoside Rb1 


\section{Shimaa A Elgaml}

could help for the treatment of kidney diseases (Kalkan et al., 2012; Karakus et al., 2011), so it plays an important role in antioxidant defense and in the elimination of free radicals. Rb1 may exert its protective effect by significantly decreasing Se redistribution or accumulation in organs (Hassan et al., 2014; Ramesh et al., 2012). Ginsenoside Rb1+Se and ginsenoside Rb1 treated groups showed an increase in the antioxidant activity when compared with Se treated group. Changes in catalase between those treated groups have been detected; little information is known to describe the difference in CAT activity between ginsenoside Rb1+Se and ginsenoside Rb1 treated groups, but these changes still not significant when compared with control.

In conclusion, the result of this study recommended the use of the herbal panax Ginseng extract, ginsenoside $\mathrm{Rb} 1$, as feed additive. Ginsenoside Rb1 can be beneficially used for future animal and poultry feed formulation. Additional studies on the other active components of panax Ginseng might be needed; biochemical and functional importance of those extracts could provide an important approach for improving the future animal and poultry health.

\section{ACKNOWLEDGEMENT}

I would like to thank Dr. Emad Hashish, the postdoctoral scholar Visitor at the Friedrich-Loeffler-Institute for Animal Health, Jena, Germany, for his help in editing and rewriting the manuscript.

\section{REFERENCES}

1. Aebi H (1984). Catalase in vitro. Methods in Enzymology 105: 121-126.

2. Agarwal R and Behari JR (2007). Role of selenium in mercury intoxication in mice. Industrial Health 45: 388-395.

3. Aldosary BM, Sutter ME, Schwartz M and Morgan BW (2012). Case series of selenium toxicity from a nutritional supplement. Clinical Toxicology 50: 57-64.

4. Atencio L, Moreno I, Jos A, Prieto AI, Moyano R, Blanco A and Camean AM (2009). Effects of dietary selenium on the oxidative stress and pathological changes in tilapia (Oreochromis niloticus) exposed to a microcystinproducing cyanobacterial water bloom. Toxicon 53: 269-282.

5. Attele AS, Wu JA and Yuan CS (1999). Ginseng pharmacology: multiple constituents and multiple actions. Biochemical Pharmacology 58: 1685-1693.

6. Barceloux DG (1999). Selenium. Journal of Toxicology 37: 145-172.

7. Berti G, Fossati P, Tarenghi G, Musitelli C, and Melzi d'Eril GV (1988). Enzymatic colorimetric method for the determination of inorganic phosphorus in serum and urine. Journal of Clinical Chemistry and Clinical Biochemistry 26: 399-404.

8. Bewick V, Cheek L and Ball J (2004). Statistics review 9: one-way analysis of variance. Critical Care 8: 130-136.

9. Chandra M, Singh B, Gupta PP, Ahuja SP and Singh N (1985). Clinicopathological, hematological, and biochemical studies in some outbreaks of nephritis in poultry. Avian Diseases 29: 590-600.

10. Cheng Y, Shen LH, Zhang JT (2005). Anti-amnestic and anti-aging effects of ginsenoside Rb1 and Rg1 and its mechanism of action. Acta Pharmacologica Sinica 26:143-149.

11. Christian GD, Knoblock EC and Purdy WC (1965). A Colometric Determination of Urea Nitrogen in Blood and Urine. Clinical Chemistry 11: 700-707.

12. Desta B, Maldonado G, Reid H, Puschner B, Maxwell J, Agasan A, Humphreys L and Holt T (2011). Acute selenium toxicosis in polo ponies. Journal of Veterinary Diagnostic Investigation 23: 623-628.

13. Elgaml SA (2014). Ameliorative effect of Korean red ginseng (Panax ginseng) on selenium induced hepatic toxicity in broilers. International Journal of Advanced Research 2 (9): 645-653.

14. Gowda S, Desai PB, Kulkarni SS, Hull VV, Math AA and Vernekar SN (2010). Markers of renal function tests. North American Journal of Medical Sciences 2: 170-173.

15. Han KL, Jung MH, Sohn JH and Hwang JK (2006). Ginsenoside 20S-protopanaxatriol (PPT) activates peroxisome proliferator-activated receptor gamma (PPARgamma) in 3T3-L1 adipocytes. Biological \& Pharmaceutical Bulletin 29: 110-113.

16. Hassan AM, Abdel-Aziem SH, El-Nekeety AA and Abdel-Wahhab MA (2014). Panax ginseng extract modulates oxidative stress, DNA fragmentation and up-regulate gene expression in rats sub chronically treated with aflatoxin $\mathrm{B}$ and fumonisin B. Cytotechnology.

17. Heinegard D and Tiderstrom G (1973). Determination of serum creatinine by a direct colorimetric method. Clinica Chimica Acta 43: 305-310.

18. Hoffman DJ (2002). Role of selenium toxicity and oxidative stress in aquatic birds. Aquatic Toxicology 57: 11-26. 
19. Huang YC, Chen CT, Chen SC, Lai PH, Liang HC, Chang Y, Yu LC and Sung HW (2005). A natural compound (ginsenoside Re) isolated from Panax ginseng as a novel angiogenic agent for tissue regeneration. Pharmaceutical Research 22: 636-646.

20. Jones MP (1999). Avian clinical pathology. The Veterinary Clinics of North America. Exotic Animal Practice 2: 663-687.

21. Kageyama N (1971). A direct colorimetric determination of uric acid in serum and urine with uricase-catalase system. Clinica Chimica Acta 31: 421-426.

22. Kalkan Y, Kapakin KA, Kara A, Atabay T, Karadeniz A, Simsek N, Karakus E, Can I, Yildirim S and Ozkanlar S (2012). Protective effect of Panax ginseng against serum biochemical changes and apoptosis in kidney of rats treated with gentamicin sulphate. Journal of Molecular Histology 43: 603-613.

23. Kamble P, Mohsin N, Jha A, Date A, Upadhaya A, Mohammad E, Khalil M, Pakkyara A and Budruddin M (2009). Selenium intoxication with selenite broth resulting in acute renal failure and severe gastriti. Saudi Journal of Kidney Diseases and Transplantation 20: 106-111.

24. Kang KS, Yamabe N, Kim HY, Park JH and Yokozawa T (2008). Therapeutic potential of 20(S)-ginsenoside Rg3 against streptozotocin-induced diabetic renal damage in rats. European Journal of Pharmacology 591: 266-272.

25. Kang KS, Park JH,Cho EJ and Yamabe N (2013). Heat-processed Panax ginseng and diabetic renal damage: active components and action mechanism. Journal Ginseng Research 37(4): 379-388.

26. Karakus E, Karadeniz A, Simsek N, Can I, Kara A, Yildirim S, Kalkan Y and Kisa F (2011). Protective effect of Panax ginseng against serum biochemical changes and apoptosis in liver of rats treated with carbon tetrachloride (CCl4). Journal of Hazardous Materials 195: 208-213.

27. Kumar D, Ganguly DN, Jana S and Pal S (2013). Effect of acute selenium toxicity in broiler birds. International Journal Advanced Innovation Research 2: 3.

28. Lee NH and Son CG (2011). Systematic review of randomized controlled trials evaluating the efficacy and safety of ginseng. Journal of Acupuncture and Meridian Studies 4: 85-97.

29. Lehnhardt A and Kemper MJ (2011). Pathogenesis, diagnosis and management of hyperkalemia. Pediatric Nephrology 26(3): 377-384.

30. Lierz M (2003). Avian renal disease: pathogenesis, diagnosis, and therapy. The Veterinary Clinics of North America. Exotic Animal Practice 6: 29-55.

31. Lumeij JT (1987). Plasma urea, creatinine and uric acid concentrations in response to dehydration in racing pigeons (Columba livia domestica). Avian Pathology 16: 377-382.

32. MacFarquhar JK, Broussard DL, Melstrom P, Hutchinson R, Wolkin A, Martin C, Burk RF, Dunn JR, Green AL, Hammond R (2010). Acute selenium toxicity associated with a dietary supplement. Archives of Internal Medicine 170: 256-261.

33. Manikandan R, Thiagarajan R, Beulaja S, Sudhandiran G and Arumugam M (2010). Curcumin protects against hepatic and renal injuries mediated by inducible nitric oxide synthase during selenium-induced toxicity in Wistar rats. Microscopy Research and Technique 73: 631-637.

34. Maraldi T, Riccio M, Zambonin L, Vinceti M, De Pol A and Hakim G (2011). Low levels of selenium compounds are selectively toxic for a human neuron cell line through ROS/RNS increase and apoptotic process activation. Neurotoxicology 32: 180-187.

35. National Research Council (NRC) (1994). Nutrient Requirements of Poultry. $7^{\text {th }}$ edn, National Academy Press, Washington DC.

36. Nuttall KL (2006). Evaluating selenium poisoning. Annals of Clinical and Laboratory Science 36: 409-420.

37. Padmaja S and Raju TN (2005). Protective effect of curcumin during selenium induced toxicity on dehydrogenases in hepatic tissue. Indian Journal of Physiology and Pharmacology 49: 111-114.

38. Peng X, Cui H, He Y, Cui W, Fang J, Zuo Z, Deng J, Pan K, Zhou Y and Lai W (2012). Excess dietary sodium selenite alters apoptotic population and oxidative stress markers of spleens in broilers. Biological Trace Element Research 145: 47-51.

39. Ramesh T, Kim SW, Sung JH, Hwang SY, Sohn SH, Yoo SK and Kim SK (2012). Effect of fermented Panax ginseng extract (GINST) on oxidative stress and antioxidant activities in major organs of aged rats. Experimental Gerontology 47: 77-84.

40. Ripoll JP (1976). Colorimetric determination of calcium in serum using methylthymol blue. Clinica Chimica Acta 72: $133-139$.

41. Ryu YC, Rhee MS, Lee KM and Kim BC (2005). Effects of different levels of dietary supplemental selenium on performance, lipid oxidation, and color stability of broiler chicks. Poultry Science 84: 809-815. 


\section{Shimaa A Elgaml}

42. Sidhu P, Garg ML and Dhawan DK (2005). Protective effects of zinc on oxidative stress enzymes in liver of protein-deficient rats. Drug and Chemical Toxicology 28: 211-230.

43. Smith AJ (1955). A colorimetric method for the estimation of serum magnesium. The Biochemical Journal 60: 522527.

44. Steinbrenner H, Speckmann B, Pinto A and Sies H (2011). High selenium intake and increased diabetes risk: experimental evidence for interplay between selenium and carbohydrate metabolism. Journal of Clinical Biochemistry and Nutrition 48: 40-45.

45. Valenzuela A (1991). The biological significance of malondialdehyde determination in the assessment of tissue oxidative stress. Life Sciences 48: 301-309.

46. Verzhikovskaia VG and Popov VV (1963). The flame photometric method of determining potassium and sodium in the blood serum. Laboratornoe Delo 41: 21-24.

47. Weydert CJ and Cullen JJ (2010). Measurement of superoxide dismutase, catalase and glutathione peroxidase in cultured cells and tissue. Nature Protocols 5: 51-66.

48. Xie JT, Wang CZ, Zhang B, Mehendale SR, Li XL, Sun S, Han AH, Du W, He TC and Yuan CS (2009). In vitro and in vivo anticancer effects of American ginseng berry: Exploring representative compounds. Biological Pharmacological Bulletin 32:1552-1558.

49. Xu JX, Cao CY, Sun YC, Wang LL, Li N, Xu SW and Li JL (2014). Effects on liver hydrogen peroxide metabolism induced by dietary selenium deficiency or excess in chickens. Biological Trace Element Research 159: 174-182.

50. Zikic RV, Stajn AS, Ognjanovic BI, Saicic ZS, Kostic MM, Pavlovic SZ and Petrovic VM (1998). The effect of cadmium and selenium on the antioxidant enzyme activities in rat heart. Journal of Environmental Pathology, Toxicology and Oncology 17: 259-264.

51. Zwolak I and Zaporowska H (2012). Selenium interactions and toxicity: a review. Selenium interactions and toxicity. Cell Biology and Toxicology 28: 31-46. 